\title{
B7 score and T cell infiltration stratify immune status in prostate cancer
}

\author{
Qianghua Zhou, ${ }^{1,2}$ Kaiwen Li, ${ }^{1,2}$ Yiming Lai, ${ }^{1,2}$ Kai Yao, ${ }^{3}$ Qiong Wang, ${ }^{1,2}$ \\ Xiangyu Zhan, ${ }^{1,2}$ Shirong Peng, ${ }^{1,2}$ Wenli Cai, ${ }^{4}$ Wei Yao, ${ }^{5}$ Xingxing Zang, ${ }^{5}$ \\ Kewei Xu, ${ }^{1,2,6}$ Jian Huang, ${ }^{1,2,6}$ Hai Huang (D) 1,2,6,7
}

To cite: Zhou Q, Li K, Lai Y, et al. B7 score and $T$ cell infiltration stratify immune status in prostate cancer. Journal for ImmunoTherapy of Cancer 2021;9:e002455. doi:10.1136/ jitc-2021-002455

- Additional supplemental material is published online only. To view, please visit the journal online (http://dx.doi.org/10. 1136/jitc-2021-002455).

$\mathrm{QZ}, \mathrm{KL}, \mathrm{YL}$ and $\mathrm{KY}$ contributed equally.

Accepted 22 July 2021
Check for updates

(c) Author(s) (or their employer(s)) 2021. Re-use permitted under CC BY-NC. No commercial re-use. See rights and permissions. Published by BMJ.

For numbered affiliations see end of article.

\section{Correspondence to}

Professor Hai Huang; huangh9@mail.sysu.edu.cn

Dr Jian Huang; huangj8@mail.sysu.edu.cn

Professor Kewei Xu; xukewei@mail.sysu.edu.cn

\section{ABSTRACT}

Background Although immune checkpoint inhibitors (ICls), especially programmed cell death protein 1 (PD1)/programmed death ligand 1 (PD-L1) axis blockers, exhibit prominent antitumor effects against numerous malignancies, their benefit for patients with prostate cancer (PCa) has been somewhat marginal. This study aimed to assess the feasibility of B7-H3 or HHLA2 as alternative immunotherapeutic targets in $\mathrm{PCa}$. Methods Immunohistochemistry was performed to evaluate the expression pattern of PD-L1, B7-H3 and HHLA2 and the infiltration of $\mathrm{CD}^{+}$and $\mathrm{Foxp}^{+}$ lymphocytes in $239 \mathrm{PCa}$ tissues from two independent cohorts. The correlations between B7-H3 and HHLA2 and clinicopathological features, including the presence of $\mathrm{CD}^{+}$and Foxp3 ${ }^{+}$tumor-infiltrating lymphocytes (TILs), were explored.

Results HHLA2 expression was much higher than PD$\mathrm{L} 1$ expression but lower than $\mathrm{B} 7-\mathrm{H} 3$ expression in $\mathrm{PCa}$ tissues. High expression of both B7-H3 and HHLA2 was significantly associated with higher Gleason score and tumor stage, lymph node metastasis and dismal overall survival (OS) and cancer-specific survival (CSS). Moreover, a high B7 score, defined as high B7-H3 expression and/ or high HHLA2 expression, was an independent prognostic predictor for $\mathrm{PCa}$. Of note, a high $\mathrm{B} 7$ score was negatively correlated with $\mathrm{CD}^{+}$TILs. Importantly, a new immune classification, based on the B7 score and CD8 ${ }^{+}$TILS, successfully stratified OS and CSS in PCa.

Conclusions Both B7-H3 and HHLA2 have a critical impact on the immunosuppressive microenvironment, and the B7 score could be used as an independent prognostic factor for PCa. The B7 score combined with $\mathrm{CD}^{+}{ }^{+}$TILs could be used as a new immune classification to stratify the risk of death, especially cancer-related death, for patients with $\mathrm{PCa}$. These findings may provide insights that could improve response to immune-related comprehensive therapy for PCa in the future.

\section{INTRODUCTION}

Based on cancer statistics, prostate cancer (PCa) is a leading cause of morbidity and mortality worldwide. ${ }^{1}$ For localised PCa, radical prostatectomy with/without radiation is the main therapeutic strategy. ${ }^{2}$ However, androgen deprivation therapy (ADT) continues to be the mainstay of therapy for patients presenting with advanced PCa or failing primary treatment, and most of them can be managed to varying degrees. ${ }^{34}$ Unfortunately, the majority of PCa cases ultimately succumb to tumor development despite the castration levels of testosterone after several years of response, referred to as castrationresistant PCa (CRPC). Treatment options for CRPC have been limited for decades. Even the next-generation antiandrogen enzalutamide provides only a palliative form of care to most patients with CRPC. ${ }^{5}$ In light of this, there is a crying need to explore new therapeutic schedules for potentiating or superseding existing treatments.

With the extensive investigation of the immune microenvironment within tumors, it is evident that tumor cells can evade immune surveillance via inhibitory checkpoint proteins (ICPs) that promote $\mathrm{T}$ cell exhaustion. Programmed death ligand 1 (PD-L1), a member of the B7 superfamily, is one of the most well-known ICPs. Elevated expression of PD-L1 on tumor cells is observed in numerous cancer types, and immune checkpoint inhibitors (ICIs) that block the PD-1/ PD-L1 axis confer prominent and durable clinical responses across cancer types, such as melanoma, lung cancer and renal cancer. ${ }^{6-8}$ The clinical benefit of PD-1/PD-L1 blockers has been reported to be correlated with high PD-L1 expression. ${ }^{9}{ }^{10}$ However, unlike the aforementioned cancer types, PD-L1 expression in PCa is rare and there are not sufficient data to warrant treatment of PCa patients with PD-1/PD-L1 axis inhibitors. ${ }^{11-13}$ Therefore, exploring other immune checkpoints as potential immunotherapeutic targets for most patients with $\mathrm{PCa}$ is worthwhile.

B7-H3 (CD276), another B7 superfamily member, is aberrantly expressed in the majority of human malignancies. However, the prognostic significance of $\mathrm{B} 7-\mathrm{H} 3$ is somewhat inconsistent among different tumors. ${ }^{14-17}$ Moreover, the function of B7-H3 in the immune response is debatable, as both coinhibitory and costimulatory roles within tumors have been 
demonstrated. ${ }^{18-21}$ These apparent discrepancies may potentially be associated with the composition of tumor-infiltrating immune cells (TIICs) within different tumors. In terms of $\mathrm{PCa}$, previous studies suggested that $\mathrm{B}$ 7-H3 is overexpressed by PCa cells and that high expression of B7-H3 is significantly associated with more aggressive phenotypes and a worse prognosis. ${ }^{22}$ However, the correlation between TIICs and B7-H3 has yet to be studied, which perhaps determines the availability of B7-H3 blockers for PCa treatment.

HERV-H LTR-associating 2 (HHLA2, B7-H7/B7-H5) is a newly identified B7 family member. Similar to B7-H3, the precise physiological function of HHLA2 has not yet been fully elucidated, as both stimulatory and inhibitory properties of HHLA2 have been reported. ${ }^{23}{ }^{24}$ Overexpression of HHLA2 has been demonstrated in several cancer types and was found to be correlated with a dismal prognosis in cholangiocarcinoma, lung cancer and renal cancer but associated with a favorable prognosis in pancreatic cancer. ${ }^{25-28}$ In addition, in our previous study, positive HHLA2 staining was observed in three out of nine PCa tissues. ${ }^{29}$ However, the clinical relevance of HHLA2 in PCa needs to be further explored.

The aim of this retrospective study was to evaluate the expression pattern and clinical significance of B7-H3 and HHLA2 and their correlations with tumorinfiltrating lymphocytes (TILs) in with PCa. In addition, we attempted to establish a novel immune classification based on B7-H3 and HHLA2 expression, and the density of tumor-infiltrating $\mathrm{T}$ cells.

\section{METHODS}

\section{Patients and samples}

We conducted a retrospective study of patients with PCa treated with radical prostatectomy at Sun Yat-sen University Cancer Center (126 cases, named training cohort) from January 2005 to December 2014, or at Sun Yat-sen Memorial Hospital (113 cases, named validation cohort) from January 2009 to December 2013. Oral consent was obtained from each patient in both cohorts. Formalinfixed, paraffin-embedded tissue blocks were available from all cases and H\&E-stained tumor slides were used to confirm the Gleason score, tumor stage and lymph node status by two senior pathologists according to the American Joint Committee on Cancer 2009 tumour, node, metastases classification for PCa. Imaging examination was used to determine distal metastasis. Overall survival (OS) was calculated from prostatectomy to death or the last follow-up, which was December 31, 2019. Cancerspecific survival (CSS) was defined as the time from prostatectomy to death from PCa or the last follow-up.

\section{Immunohistochemistry}

In line with our previous study, ${ }^{30}$ briefly, formalin-fixed PCa tissue sections were paraffinized in xylene and hydrated in a diluted alcohol series. Then, antigen retrieval was accomplished with sodium citrate buffer (10 $\mathrm{mM}, \mathrm{pH}$ 6.0) using a microwave for $10 \mathrm{~min}$. After that, the sections were immersed in $\mathrm{H}_{2} \mathrm{O}_{2}(0.3 \%)$ for $15 \mathrm{~min}$ to reduce activity of endogenous peroxidase. Following blocking with goat serum, the sections were incubated with corresponding primary antibodies (anti-PD-L1: Cell Signaling Technology (CST) \#13684; anti-B7-H3: CST, \#14058; anti-HHLA2: clone 566.1 ${ }^{29}$; anti-CD8: CST, \#85336; anti-Foxp3: CST, \#12653) at $4^{\circ} \mathrm{C}$ overnight. Then, after washing for three times using phosphate buffered saline (PBS), the sections were subsequently incubated with secondary antibody for 1 hour. Finally, the sections were visualized using a DAKO EnVision Detection System (Dako) and counterstained with hematoxylin.

\section{Assessment of PD-L1, B7-H3 and HHLA2 expression and the density of infiltrated immune cells}

All sections were assessed by two independent pathologists blinded to the clinical profiles of the patients, and discrepancies were resolved after consensus. PD-L1 positivity in this study was defined as PD-L1 staining in $\geq 1 \%$ of tumor cells. ${ }^{31}$ Both B7-H3 and HHLA2 immunostaining in tumor cells were semi-quantified using the H-score on account of the percentage of positive staining and the staining intensity. In detail, the staining intensity was divided into four levels as follows: absent (0), weak (1), moderate (2) and strong (3) (online supplemental figure S1A,B). The H-score of each case was determined by multiplying the staining intensity by the corresponding percentage of positive cells. The H-score range was 0 to 300 . An $\mathrm{H}$-score $>0$ was defined as positive expression and the cut-off values for differentiating high and low B7-H3 and HHLA2 expression were 120 and 80 determined by $\mathrm{X}$-tile program, respectively.

The infiltration extent of $\mathrm{CD}^{+}$and Foxp $3^{+}$TILs was evaluated according to the mean of counts in five independent high-power fields $(400 \times)$ within mesenchyme, which represented the densest immune cell infiltrates. The mean value was considered the cut-off point for marker stratifications in this study. ${ }^{25}$

\section{Statistical analysis}

The distribution of clinicopathological parameters, including the densities of different sets of immune cells over B7-H3 or HHLA2 expression categories, was evaluated using $\chi^{2}$ or Fisher's exact test. The OS and CSS curves were depicted with the Kaplan-Meier method, and the intergroup differences were examined using a logrank test. Cox proportional hazard regression analysis was performed for univariate and multivariate analyses. All statistical analyses were performed using SPSS V.24.0 (Chicago, Illinois, USA) or GraphPad Prism V.8 (La Jolla, California, USA) software.

\section{RESULTS}

\section{Clinicopathological characteristics of patients with PCa}

The basic clinicopathological characteristics of 239 patients with PCa from two independent cohorts are summed up in online supplemental table 1 . The mean age at operation was 66 years (range, 42-86) in the 
A
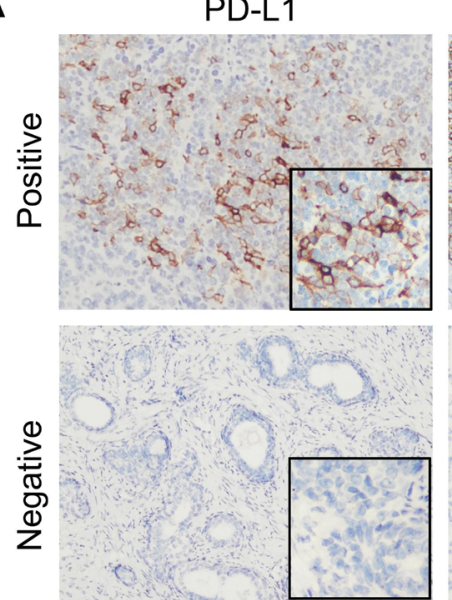

B

- PD-L1 negative PD-L1 positive

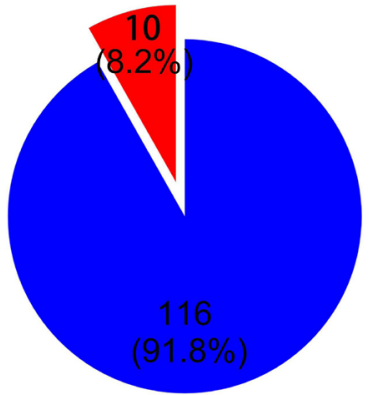

Training cohort $(n=126)$

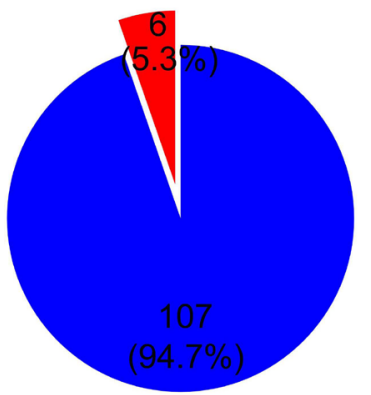

Validation cohort $(n=113)$
B7-H3
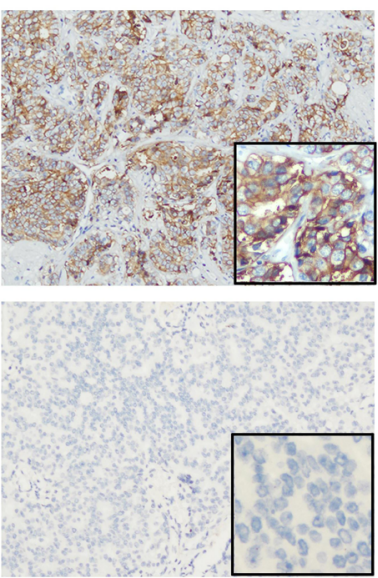

C

B7-H3 negative

B7-H3 positive

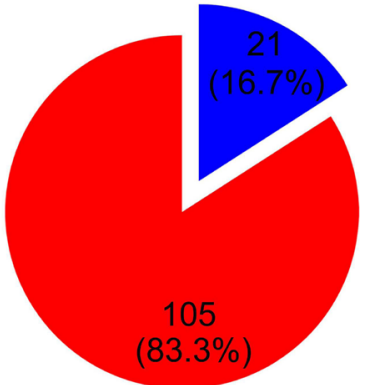

Training cohort $(n=126)$

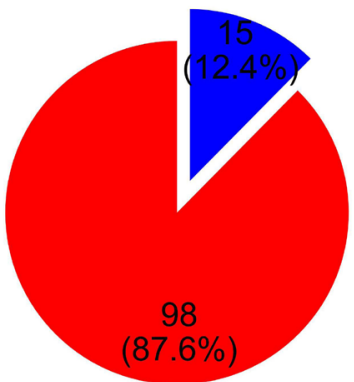

Validation cohort $(n=113)$

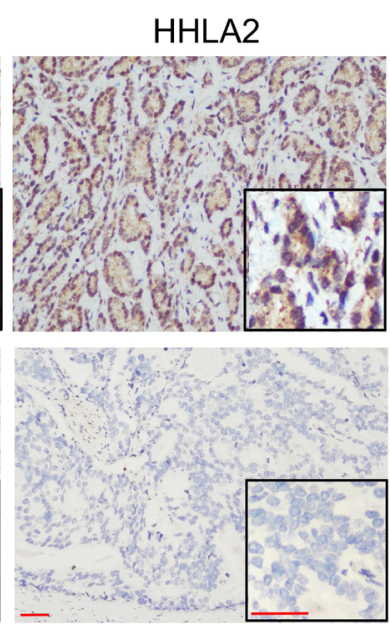

D

HHLA2 negative HHLA2 positive

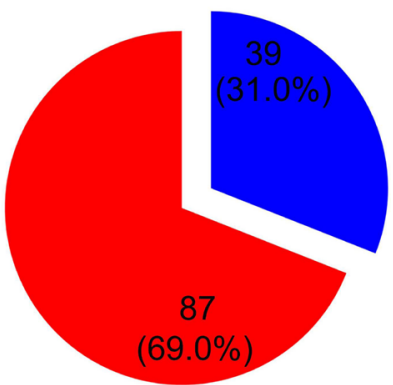

Training cohort $(n=126)$

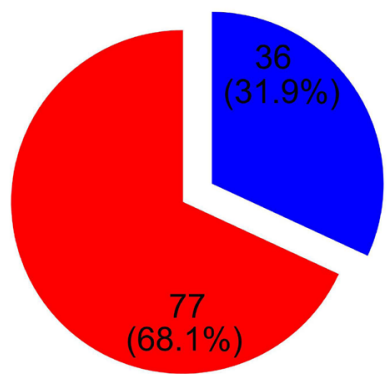

Validation cohort $(n=113)$

Figure 1 Programmed death ligand 1 (PD-L1), B7-H3 and HHLA2 expression in prostate cancer (PCa) tissue sample. (A) Representative immunohistochemical staining of PD-L1, B7-H3 and HHLA2 within tumor, scale bar, $50 \mu \mathrm{m}$. (B) The positive rate of PD-L1 in PCa tissues were $8.2 \%$ and $5.3 \%$ in indicated cohorts, respectively. (C) The positive rate of B7-H3 in PCa tissues were $83.3 \%$ and $87.6 \%$ in indicated cohorts, respectively. (D) The positive rate of HHLA2 in PCa tissues were $69.0 \%$ and $68.1 \%$ in indicated cohorts, respectively.

training cohort and 69 years (range, 52-89) in the validation cohort, respectively. At the end of follow-up, 36 (28.6\%) patients died, including $25(19.8 \%)$ cases died from tumor progression in the training cohort. The median follow-up time was 88.5 months (range, 4-171). The 5-year and 10 -year OS rates were $81.4 \%$ and $64.7 \%$, respectively, and the 5-year and 10-year CSS rates were $85.0 \%$ and $73.2 \%$, respectively. In the validation cohort, $22(19.5 \%)$ patients died, including 15 (13.3\%) cases died from tumor progression, and the median follow-up time was 78.0 months (range, 1-126). The 5-year and 10 -year OS rates were $84.2 \%$ and $78.5 \%$, respectively, and the 5-year and 10-year CSS rates were $87.8 \%$ and $85.4 \%$, respectively.

\section{PD-L1, B7-H3 and HHLA2 expression in PCa}

To evaluate the expression spectrum of PD-L1, B7-H3 and HHLA2 in PCa tissues from the two cohorts, immunohistochemistry (IHC) was performed, and typical IHC photomicrographs of PD-L1, B7-H3 and HHLA2 
Table 1 The correlation of B7-H3 and HHLA2 expression with clinicopathological features in both cohorts

\begin{tabular}{|c|c|c|c|c|c|c|c|c|c|c|c|c|c|c|}
\hline \multirow[b]{3}{*}{ Variables } & \multicolumn{7}{|c|}{ Training cohort } & \multicolumn{7}{|c|}{ Validation cohort } \\
\hline & \multirow[b]{2}{*}{$\begin{array}{l}\text { Patients } \\
\text { no. }\end{array}$} & \multicolumn{3}{|c|}{ B7-H3 expression } & \multicolumn{3}{|c|}{ HHLA2 expression } & \multirow[b]{2}{*}{$\begin{array}{l}\text { Patients } \\
\text { no. }\end{array}$} & \multicolumn{3}{|c|}{ B7-H3 expression } & \multicolumn{3}{|c|}{ HHLA2 expression } \\
\hline & & Low & High & $\begin{array}{l}P \\
\text { value }\end{array}$ & Low & High & $\begin{array}{l}P \\
\text { value }\end{array}$ & & Low & High & $\begin{array}{l}P \\
\text { value }\end{array}$ & Low & High & $\begin{array}{l}P \\
\text { value }\end{array}$ \\
\hline Age (years) & & & & 0.15 & & & 0.15 & & & & 0.034 & & & 0.647 \\
\hline$<66$ & 59 & 25 & 34 & & 34 & 25 & & 41 & 31 & 10 & & 25 & 16 & \\
\hline $6-7(3+4)$ & 65 & 38 & 27 & & 42 & 23 & & 54 & 41 & 13 & & 40 & 14 & \\
\hline $7(4+3)-10$ & 61 & 24 & 37 & & 22 & 39 & & 59 & 30 & 19 & & 32 & 27 & \\
\hline Tumor stage & & & & 0.006 & & & 0.049 & & & & 0.001 & & & 0.031 \\
\hline T2 & 76 & 45 & 31 & & 44 & 32 & & 80 & 58 & 22 & & 56 & 24 & \\
\hline Absent & 108 & 60 & 57 & & 61 & 47 & & 110 & 69 & 41 & & 72 & 38 & \\
\hline Present & 18 & 2 & 7 & & 3 & 15 & & 3 & 2 & 1 & & 0 & 3 & \\
\hline $\begin{array}{l}\text { Distal } \\
\text { metastasis }\end{array}$ & & & & 0.324 & & & 0.052 & & & & 0.145 & & & 0.709 \\
\hline Absent & 116 & 59 & 52 & & 62 & 54 & & 105 & 68 & 37 & & 66 & 39 & \\
\hline Present & 10 & 3 & 39 & & 2 & 8 & & 8 & 3 & 5 & & 6 & 2 & \\
\hline $\begin{array}{l}\text { B7-H3 } \\
\text { expression }\end{array}$ & & & & - & & & 0.002 & & & & - & & & 0.02 \\
\hline Low & 62 & - & - & & 40 & 22 & & 71 & - & - & & 51 & 20 & \\
\hline
\end{tabular}

$P$ values $<0.05$ marked in bold font are statistically significant.

expression are presented in figure 1A. PD-L1 was positively stained in $10(8.2 \%)$ cases in the training cohort and $6(5.3 \%)$ cases in the validation cohort (figure $1 \mathrm{~B})$. However, B7-H3 was widely expressed in $105(83.3 \%)$ PCa cases in the training cohort and $98(87.6 \%)$ cases in the validation cohort (figure 1C). In terms of HHLA2, positive staining of HHLA2 was detectable in $87(69.0 \%)$ and $77(68.1 \%)$ PCa cases in the two cohorts, respectively (figure 1D). These data demonstrate that B7-H3 and HHLA2 are more frequently expressed in PCa tissues, compared with PD-L1 expression.

\section{Association between B7-H3 and HHLA2 and clinicopathological factors in patients with $\mathrm{PCa}$}

To evaluate the clinical relevance of B7-H3 and HHLA2, the patients with $\mathrm{PCa}$ were segregated into two groups according to the optimal cut-off value for the $\mathrm{H}$-score of B7-H3 (H-score=120) or HHLA2 (H-score=80). As detailed in table 1, high B7-H3 expression (H-score $\geq 120$ ) was significantly associated with advanced Gleason score ( $p=0.032$ and $p=0.006$, respectively) and tumor stage ( $p=0.006$ and $p=0.001$, respectively) in both cohorts. Furthermore, high expression of B7-H3 was also significantly correlated with lymph node metastasis in the training cohort $(\mathrm{p}=0.001$, table 1$)$. Similarly, in both cohorts, increased HHLA2 expression (H-score $\geq 80$ ) displayed a significant correlation with advanced Gleason score $(\mathrm{p}=0.001$ and $\mathrm{p}=0.028$, respectively), tumor stage $(\mathrm{p}=0.049$ and $\mathrm{p}=0.031$, respectively) and lymph node metastasis $(\mathrm{p}=0.002$ and $\mathrm{p}=0.046$, respectively) (table 1$)$. Of note, significant associations were detected between B7-H3 and HHLA2 expression in both cohorts $(p=0.002$ and $\mathrm{p}=0.020$, respectively, table 1 ). Taken together, these data show that high expression of both B7-H3 and HHLA2 might be associated with worse clinicopathological features.

\section{Correlation between B7-H3, HHLA2 and TILs in PCa}

Microphotographs of $\mathrm{CD}^{+}$and Foxp $3^{+}$TILs are shown in figure 2A. The density of $\mathrm{CD}^{+}$TILs was much higher than the density of Foxp $3^{+}$TILs in both cohorts $(p<0.001$ in both cohorts, figure $2 \mathrm{~B}$ ). In both cohorts, significantly higher densities of CD8 ${ }^{+}$TILs were detected in tumors with low B7-H3 or HHLA2 expression than in tumors with high B7-H3 or HHLA2 expression (training cohort: B7-H3, $\mathrm{p}<0.001$, HHLA2, $\mathrm{p}<0.001$; validation cohort: $\mathrm{B} 7-\mathrm{H} 3$, $\mathrm{p}<0.01$, HHLA2, $\mathrm{p}<0.001$; figure 2C-D). Conversely, no significant differences in Foxp $3^{+}$TILs were observed 
A

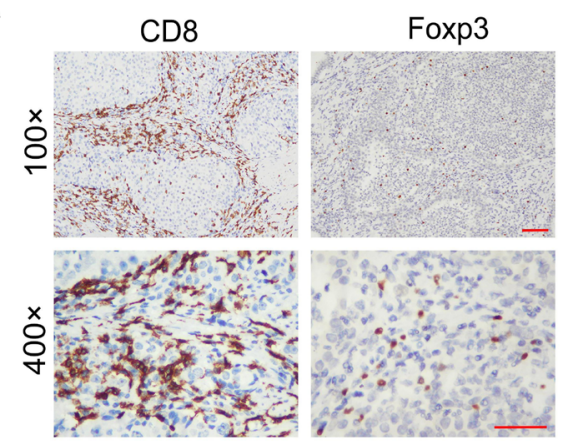

C

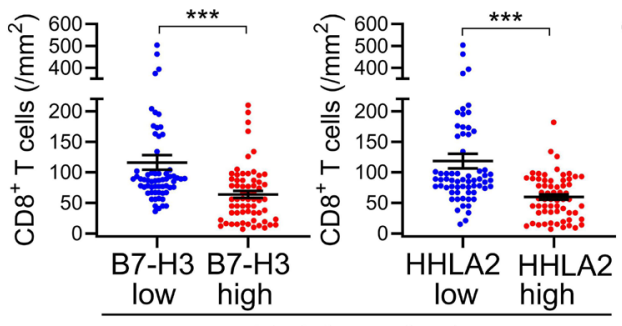

Training cohort

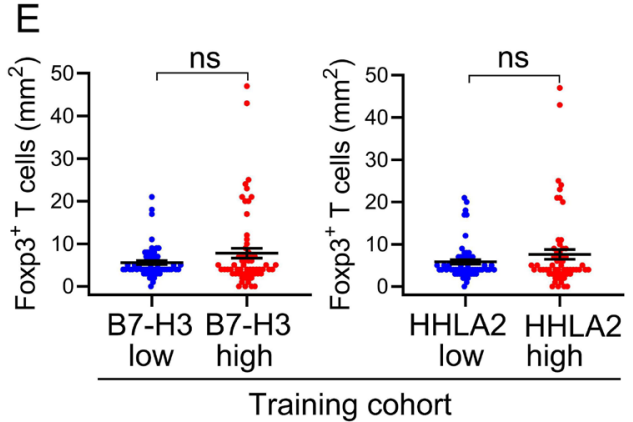

B

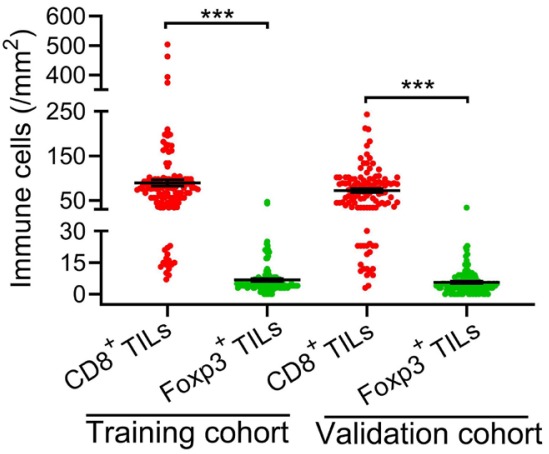

D

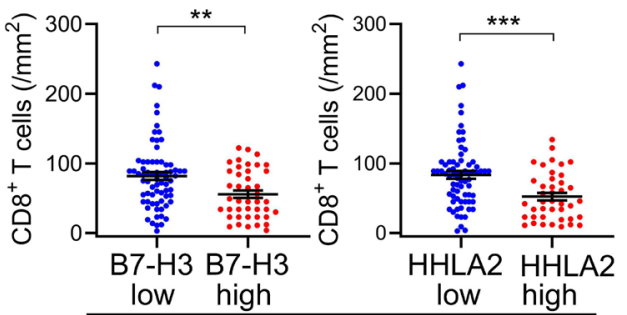

Validation cohort

F

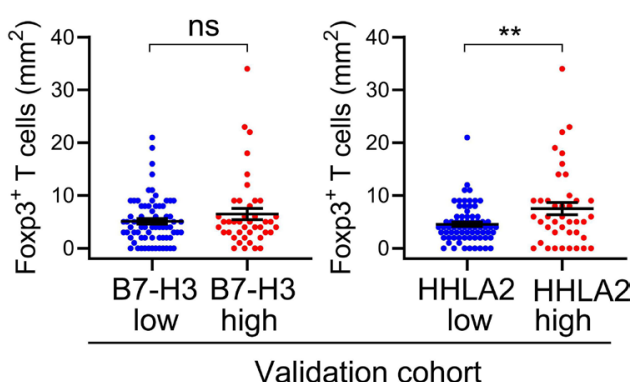

Figure 2 The association of B7-H3 or HHLA2 expression with tumor-infiltrating lymphocytes (TILs). (A) Representative micrographs of CD8 and Foxp3 expression within the tumor, scale bar, $50 \mu \mathrm{m}$. (B) Scatter plot depicted the density of CD8 ${ }^{+}$ or Foxp $3^{+}$TILs in indicated cohorts. (C-D) The counts of CD8 $8^{+}$TILs in tumors with different B7-H3 or HHLA2 expression in indicated cohorts. (E-F) The counts of Foxp3 ${ }^{+}$TILs in tumors with different B7-H3 or HHLA2 expression in indicated cohorts. Error bars indicate median with SEM, ${ }^{* \star} \mathrm{p}<0.01,{ }^{* \star *} \mathrm{p}<0.001, \mathrm{~ns}$, no significance.

between tumors with high B7-H3 expression and tumors with low B7-H3 in either cohort (figure 2E-F). Similarly, no significant correlation was observed between HHLA2 expression and Foxp3 $3^{+}$TILs in the training cohort (figure 2E). However, a high density of Foxp3 $3^{+}$TILs was significantly associated with high HHLA2 expression in the validation cohort $(p<0.01$, figure $2 F)$. These results indicate that both B7-H3 and HHLA2 might account for the immunosuppressive environment within PCa tissues.

\section{The prognostic significance of $\mathrm{B} 7-\mathrm{H} 3$ and HHLA2 in patients with PCa}

Given the prevalence of B7-H3 and HHLA2 overexpression, a univariate analysis of OS and CSS was generated to evaluate the prognostic significance of $\mathrm{B} 7-\mathrm{H} 3$ and HHLA2 expression. Interestingly, high B7-H3 expression conferred a greater than twofold increase in the risk of mortality, especially CSS, in both cohorts (OS: training cohort, $\mathrm{HR}=2.70,95 \% \mathrm{CI}=1.33$ to $5.50, \mathrm{p}=0.006$; validation cohort, $\mathrm{HR}=2.85,95 \% \mathrm{CI}=1.21$ to $6.68, \mathrm{p}=0.016$; $\mathrm{CSS}$ : training cohort, $\mathrm{HR}=3.01,95 \% \mathrm{CI}=1.26$ to $7.24, \mathrm{p}=0.014$; validation cohort, $\mathrm{HR}=2.90,95 \% \mathrm{CI}=1.03$ to 8.17 , $\mathrm{p}=0.043$; table 2). Similarly, Kaplan-Meier analyses demonstrated that patients with high B7-H3 expression had shorter OS and CSS than those with low expression of B7-H3 in both cohorts (for the training cohort, OS: $\mathrm{p}=0.004$, CSS: $\mathrm{p}=0.009$; for the validation cohort, OS: $\mathrm{p}=0.011$, CSS: $\mathrm{p}=0.034$; figure $3 \mathrm{~A}-\mathrm{B}$ ).

In line with the results for $\mathrm{B} 7-\mathrm{H} 3$, patients with high HHLA2 expression demonstrated significantly lower OS, especially CSS, than patients with low HHLA2 expression in both cohorts (OS: training cohort, $\mathrm{HR}=2.73,95 \%$ $\mathrm{CI}=1.31$ to $5.69, \mathrm{p}=0.007$; validation cohort, $\mathrm{HR}=3.70$, $95 \% \mathrm{CI}=1.55$ to $8.83, \mathrm{p}=0.003$; CSS: training cohort, $\mathrm{HR}=3.44,95 \% \mathrm{CI}=1.37$ to $8.65, \mathrm{p}=0.008$; validation cohort, HR=3.06, 95\% CI=1.09 to 8.62, $\mathrm{p}=0.034$; table 2). Furthermore, high HHLA2 expression was demonstrated to contribute to shorter survival of patients with PCa in both cohorts (for the training cohort, OS: $\mathrm{p}=0.005$, CSS: 
Table 2 Univariate analysis of prognostic factors correlated with OS and CSS

\begin{tabular}{|c|c|c|c|c|c|c|c|c|}
\hline \multirow[b]{3}{*}{ Variables } & \multicolumn{4}{|l|}{ OS } & \multicolumn{4}{|l|}{ css } \\
\hline & \multicolumn{2}{|c|}{ Training cohort } & \multicolumn{2}{|c|}{ Validation cohort } & \multicolumn{2}{|c|}{ Training cohort } & \multicolumn{2}{|c|}{ Validation cohort } \\
\hline & HR (95\% Cl) & $P$ value & HR (95\% Cl) & P value & HR (95\% Cl) & $P$ value & HR (95\% Cl) & $P$ value \\
\hline Age (years) & 1.94 & 0.059 & 1.62 & 0.341 & 1.89 & 0.129 & 1.21 & 0.713 \\
\hline$\geq 66 /<66$ & $0.98-3.88$ & & $0.63-4.14$ & & $0.83-4.32$ & & $0.43-3.41$ & \\
\hline \multirow{2}{*}{$\begin{array}{l}\text { Gleason score } 7 \\
(4+3)-10 / 6-7(3+4)\end{array}$} & 2.58 & 0.009 & 7.28 & 0.001 & 2.46 & 0.036 & 7.06 & 0.01 \\
\hline & $1.27-5.24$ & & $2.14-24.67$ & & $1.06-5.71$ & & $1.59-31.39$ & \\
\hline Tumor stage & 2.14 & 0.025 & 5.5 & $<0.001$ & 2.3 & 0.042 & 6.03 & 0.001 \\
\hline T3-4/T2 & $1.10-4.17$ & & $2.30-13.16$ & & $1.03-5.13$ & & $2.06-17.71$ & \\
\hline Nodal metastasis & 3.86 & $<0.001$ & 5.72 & 0.021 & 4.45 & $<0.001$ & 7.18 & 0.011 \\
\hline Present/Absent & $1.90-7.83$ & & $1.30-25.27$ & & $1.94-10.16$ & & $1.59-32.56$ & \\
\hline Distal metastasis & 5.83 & $<0.001$ & 4.43 & 0.003 & 6.49 & $<0.001$ & 7.27 & $<0.001$ \\
\hline Present/Absent & $2.63-12.93$ & & $1.63-12.03$ & & $2.56-16.43$ & & $2.48-21.30$ & \\
\hline $\mathrm{B} 7-\mathrm{H} 3$ & 2.7 & 0.006 & 2.85 & 0.016 & 3.01 & 0.014 & 2.9 & 0.043 \\
\hline High/Low & $1.33-5.50$ & & $1.21-6.68$ & & $1.26-7.24$ & & $1.03-8.17$ & \\
\hline HHLA2 & 2.73 & 0.007 & 3.7 & 0.003 & 3.44 & 0.008 & 3.06 & 0.034 \\
\hline High/Low & $1.31-5.69$ & & $1.55-8.83$ & & $1.37-8.65$ & & $1.09-8.62$ & \\
\hline
\end{tabular}

$P$ values $<0.05$ marked in bold font are statistically significant.

CSS, cancer-specific survival; OS, overall survival.

$\mathrm{p}=0.005$; for the validation cohort, OS: $\mathrm{p}=0.002$, CSS: $\mathrm{p}=0.025$; figure $3 \mathrm{C}-\mathrm{D}$ ).

Multivariate analysis revealed that neither B7-H3 nor HHLA2 were independent risk factors for OS and CSS in the training cohort (table 3). However, HHLA2 was identified as an independent risk factor for OS in the validation cohort $(\mathrm{HR}=3.15,95 \% \mathrm{CI}=1.10$ to $9.00, \mathrm{p}=0.032$, table 3).

\section{Association of B7 score with prognosis and tumor-infiltrating immune cells}

A previous study demonstrated that extensive infiltration of $\mathrm{CD}^{+}$TILs can independently predict a favorable prognosis in $\mathrm{PCa} .{ }^{32}$ Considering the close correlation between B7-H3 and HHLA2 and the infiltration of CD8 $8^{+}$TILs, it is confusing that neither B7-H3 nor HHLA2 were independent prognostic factors. To further determine the relationship between $\mathrm{B} 7-\mathrm{H} 3$ and/or HHLA2 expression and the prognosis of patients with PCa, we attempted to generate a potential tool for predicting survival, based on the expression of B7-H3 and HHLA2. The patients with PCa were presorted into four groups according to the expression of B7-H3 and HHLA2 as follows: group I $\left(\right.$ B7-H3 ${ }^{\text {low }} /$ HHLA2 $\left.^{\text {low }}\right)$, group II (B7-H3 ${ }^{\text {low }} /$ HHLA $\left.^{\text {high }}\right)$, group III (B7-H3 $3^{\text {high }} / \mathrm{HHLA}^{\text {low }}$ ) and group IV (B7-H$3^{\text {high }} /$ HHLA $\left.2^{\text {high }}\right)$. In both cohorts, Kaplan-Meier analysis demonstrated that patients in groups II-IV experienced shorter OS and CSS than patients in group I (online supplemental figure S2A,B). However, no significant difference was detected among patients in groups II-IV in both cohorts (online supplemental figure S2A,B). Thus, we then divided the patients into two groups: low
B7 score, B7-H3 ${ }^{\text {low }} / \mathrm{HHLA}^{\text {low }}$; high $\mathrm{B} 7$ score, $\mathrm{B} 7-\mathrm{H} 3^{\text {low }} /$ HHLA2 $2^{\text {high }}$ ，B7-H $3^{\text {high }} / \mathrm{HHLA}^{\text {low }}$ or $\mathrm{B} 7-\mathrm{H} 3^{\text {high }} / \mathrm{HHLA}-$ $2^{\text {high }}$. As shown in online supplemental table S2, a high B7 score was significantly associated with advanced Gleason score $(p=0.040$ and $p=0.001$, respectively) and tumor stage $(p=0.022$ and $p=0.002$, respectively) in the two cohorts. Moreover, a high B7 score was significantly correlated with lymph node metastasis in the training cohort ( $\mathrm{p}=0.010$, online supplemental table S2). KaplanMeier analysis also demonstrated that high B7 score significantly stratified OS and CSS in both cohorts (for the training cohort, OS: $p=0.001$, CSS: $p=0.004$; for the validation cohort, OS: $\mathrm{p}<0.001$, CSS: $\mathrm{p}=0.002$; figure $4 \mathrm{~A}, \mathrm{~B}$ ). More importantly, in a multivariate analysis, patients with high B7 score were still over four times more likely to die, especially from tumor-related factors, after adjusting for possible confounding variables in the training cohort $(\mathrm{OS}: \mathrm{HR}=4.33,95 \% \mathrm{CI}=1.29$ to $14.56, \mathrm{p}=0.018$; CSS: $\mathrm{HR}=4.54,95 \% \mathrm{CI}=1.03$ to $20.02, \mathrm{p}=0.046$; table 4 ). In the validation cohort, the B7 score was an independent predictor for OS and tended to be an independent predictor for CSS (OS: HR=10.76, 95\% CI $=1.41$ to 82.50 , $\mathrm{p}=0.022$; CSS: $\mathrm{HR}=6.52,95 \% \mathrm{CI}=0.82$ to 52.09 , $\mathrm{p}=0.077$; table 4). Of note, a high B7 score was inversely associated with a high density of CD8 $8^{+}$TILs $(p<0.001$ in both cohorts, figure 4C). However, no correlation was detected between Foxp $3^{+}$TILs and B7-H3 or HHLA2 expression in either cohort (figure 4C).

To sum up, these data indicate that the combination of B7-H3 and HHLA2 expression might have better prognostic value in patients with PCa. 
A

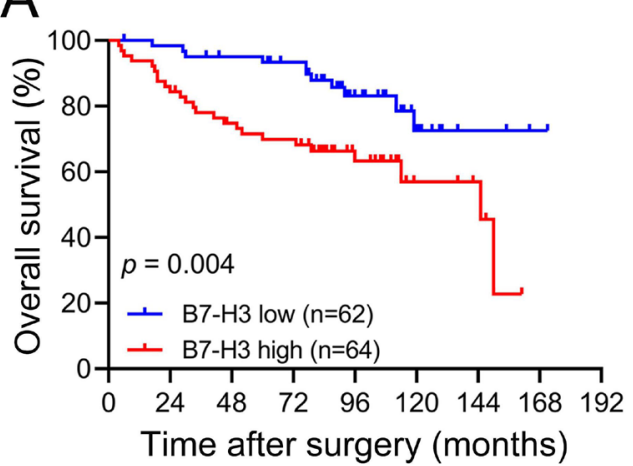

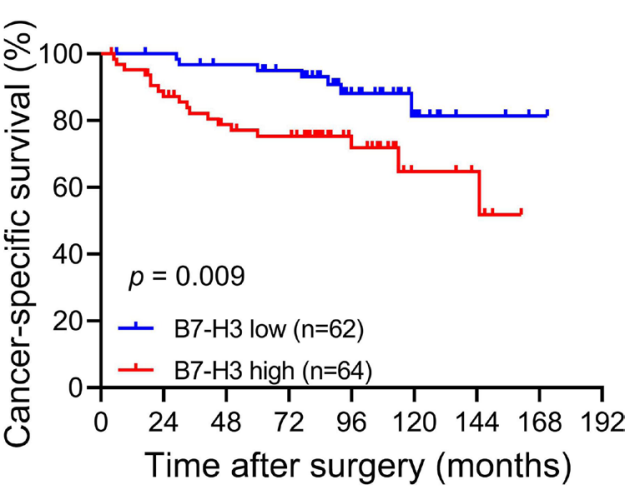

Training Cohort

B

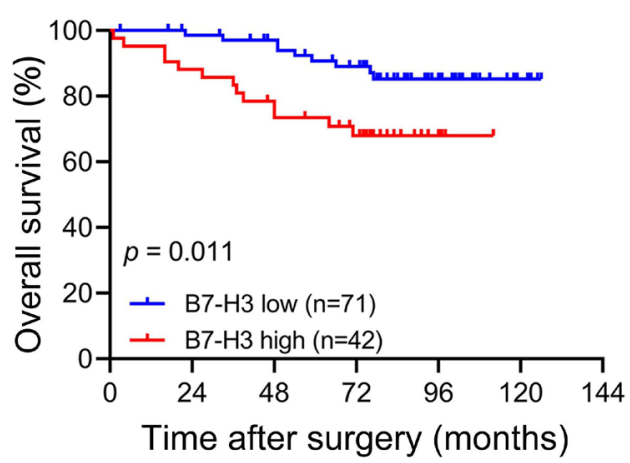

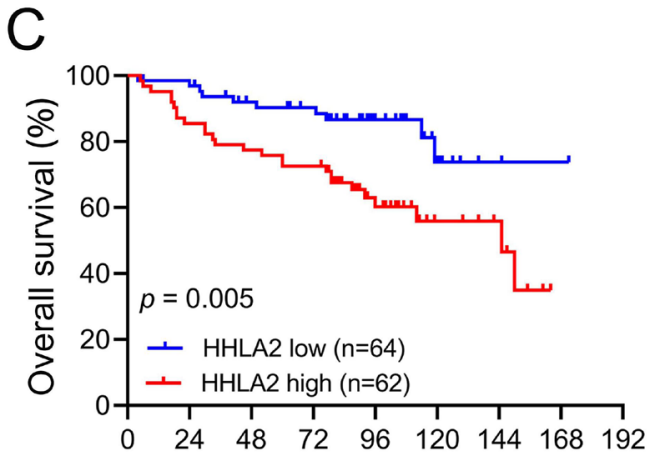

Validation Cohort

Time after surgery (months)

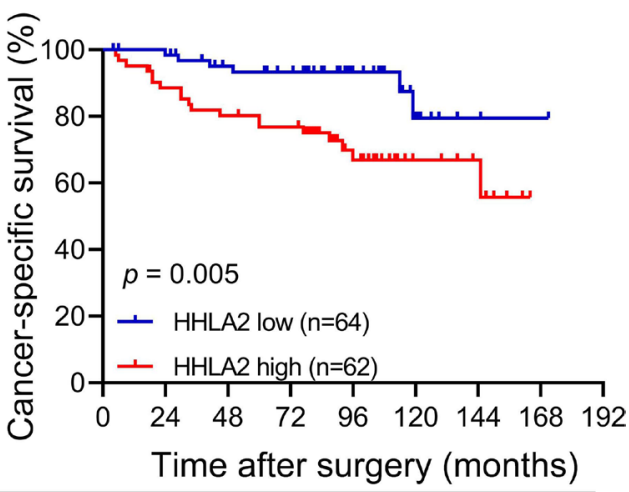

\section{Training Cohort}

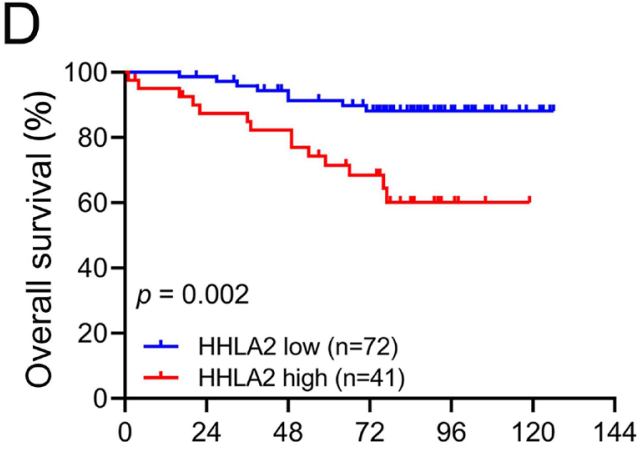

Time after surgery (months)

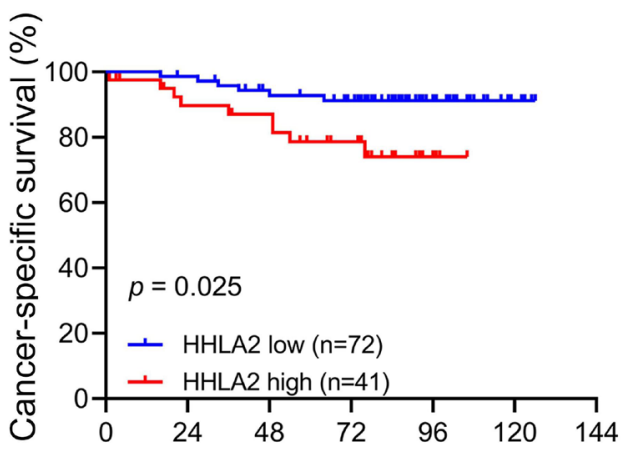

Time after surgery (months)

\section{Validation Cohort}

Figure 3 Association of B7-H3 or HHLA2 expression with overall survival (OS) and cancer-specific survival (CSS) depicted by Kaplan-Meier survival curves. (A-B) OS and CSS according to B7-H3 expression in indicated cohort. (C-D) OS and CSS according to HHLA2 expression in indicated cohort. 
Table 3 Multivariate analysis of prognostic factors correlated with OS and CSS with regard to B7-H3 and HHLA2

\begin{tabular}{|c|c|c|c|c|c|c|c|c|}
\hline \multirow[b]{3}{*}{ Variables } & \multicolumn{4}{|l|}{ os } & \multicolumn{4}{|l|}{ CSS } \\
\hline & \multicolumn{2}{|c|}{ Training cohort } & \multicolumn{2}{|c|}{ Validation cohort } & \multicolumn{2}{|c|}{ Training cohort } & \multicolumn{2}{|c|}{ Validation cohort } \\
\hline & HR (95\% Cl) & $P$ value & HR (95\% Cl) & P value & HR (95\% Cl) & $P$ value & HR (95\% Cl) & $P$ value \\
\hline $\begin{array}{l}\text { Gleason score } 7 \\
(4+3)-10 / 6-7(3+4)\end{array}$ & 0.65 to 3.52 & 0.344 & 1.30 to 15.71 & 0.018 & 0.42 to 3.46 & 0.723 & 0.85 to 18.34 & 0.08 \\
\hline Tumor stage & 0.96 & 0.928 & 3.22 & $<0.001$ & 1 & 0.999 & 3.08 & 0.07 \\
\hline Nodal metastasis & 2.3 & \multirow[t]{2}{*}{0.065} & 1.6 & \multirow[t]{2}{*}{0.609} & 2.69 & \multirow[t]{2}{*}{0.061} & 1.54 & \multirow[t]{2}{*}{0.667} \\
\hline Present/Absent & 0.95 to 5.55 & & 0.27 to 9.64 & & 0.96 to 7.60 & & 0.22 to 10.98 & \\
\hline Distal metastasis & 6.47 & \multirow[t]{2}{*}{$<0.001$} & 2.35 & \multirow[t]{2}{*}{0.212} & 7.65 & \multirow[t]{2}{*}{$<0.001$} & 3.87 & \multirow[t]{2}{*}{0.082} \\
\hline Present/Absent & 2.76 to 15.18 & & 0.61 to 9.02 & & 2.79 to 21.00 & & 0.84 to 17.76 & \\
\hline B7-H3 & 2.03 & 0.082 & 1.39 & 0.47 & 2.13 & 0.13 & 1.27 & 0.674 \\
\hline High/Low & 0.68 to 3.53 & 0.297 & 1.10 to 9.00 & 0.032 & 0.72 to 5.66 & 0.185 & 0.80 to 11.30 & 0.102 \\
\hline
\end{tabular}

$P$ values $<0.05$ marked in bold font are statistically significant.

CSS, cancer-specific survival; OS, overall survival.

\section{Development of a novel immune classification based on the B7 score and CD8 ${ }^{+}$TILs}

Based on the above findings, we developed a novel immune classification scheme according to the B7 score and the density of $\mathrm{CD}^{+}$TILs. Specifically, the patients with PCa were classified into four immune types: immune type I (low B7 score, high CD8 ${ }^{+}$TILs), immune type II (low B7 score, low $\mathrm{CD} 8^{+}$TILs), immune type III (high B7 score, high CD8 $8^{+}$TILs) and immune type IV (high B7 score, low CD8 ${ }^{+}$TILs). The proportions of patients with PCa with immune types I, II, III and IV were $14.3 \%$ $(18 / 126), 17.5 \%$ (22/126), 22\% (22/126) and 50.8\% $(64 / 126)$, respectively in the training cohort. Of 113 patients with $\mathrm{PCa}$ from the validation cohort, 29.2\% $(\mathrm{n}=33)$ belonged to immune type I, $14.2 \% \quad(\mathrm{n}=16)$ belonged to immune type II, $18.6 \%(n=21)$ belonged to immune type III and $38.1 \%(\mathrm{n}=43)$ belonged to immune type IV. According to the Kaplan-Meier analysis, immune type IV was more significantly correlated with the poorest OS and CSS among patients with the four immune types in both cohorts (figure 5A-B). Conversely, immune type I was significantly correlated with improved OS and CSS in both cohorts, even no death was observed during the follow-up (figure 5A-B). However, no difference in OS and CSS was found between immune type II or III in either cohort (figure 5A-B). These data demonstrate that this novel immune classification might provide direction for predicting prognosis and immunotherapy results.

\section{DISCUSSION}

As far as we know, this is the first comprehensive study measuring the expression pattern of three different B7-family member ligands (PD-L1, B7-H3 and HHLA2) in two sizeable cohorts of patients with PCa. We found that positive HHLA2 staining was much more frequent than positive PD-L1 staining, but relatively less prevalent than positive B7-H3 staining. Moreover, our results are the first to demonstrate that high HHLA2 expression is significantly correlated with worse clinicopathological features, including higher Gleason score, tumor stage and lymph node metastasis, and shorter OS and CSS, in keeping with the clinical relevance of B7-H3 in PCa, which has been described in our previous studies and was confirmed in present study. ${ }^{33}$ These data indicate that both B7-H3 and HHLA2 might mediate immune evasion in PCa and are potential targets for immunotherapy.

Although both B7-H3 and HHLA2 have similar immunological functions and our data showed a significant association between B7-H3 and HHLA2, simultaneous overexpression of $\mathrm{B} 7-\mathrm{H} 3$ and HHLA2 was detected in only $31 \%$ of the PCa cases in the training cohort and $18 \%$ of the PCa cases in the validation cohort. These results suggest that overexpression of B7-H3 or HHLA2 may inhibit the activation and proliferation of $\mathrm{T}$ cells via non-redundant/exclusive inhibitory pathways. Given the infrequent co-overexpression of B7-H3 and HHLA2, we were the first to evaluate the prognosis of patients with PCa by combining B7-H3 with HHLA2. We found that a high $\mathrm{B} 7$ score, including $\mathrm{B} 7-\mathrm{H} 3^{\text {low }} / \mathrm{HHLA}^{\text {high }}$, B7-H$3^{\text {high }} /$ HHLA2 $^{\text {low }}$ or $\mathrm{B} 7-\mathrm{H} 3^{\text {high }} / \mathrm{HHLA} 2^{\text {high }}$, was significantly associated with detrimental clinicopathological features and a poor prognosis. Furthermore, it was an independent prognostic factor for OS and CSS. These data indicate that B7-H3 combined with HHLA2 displays better value in predicting the prognosis of patients with PCa. These findings might also direct immunotherapy for 
A

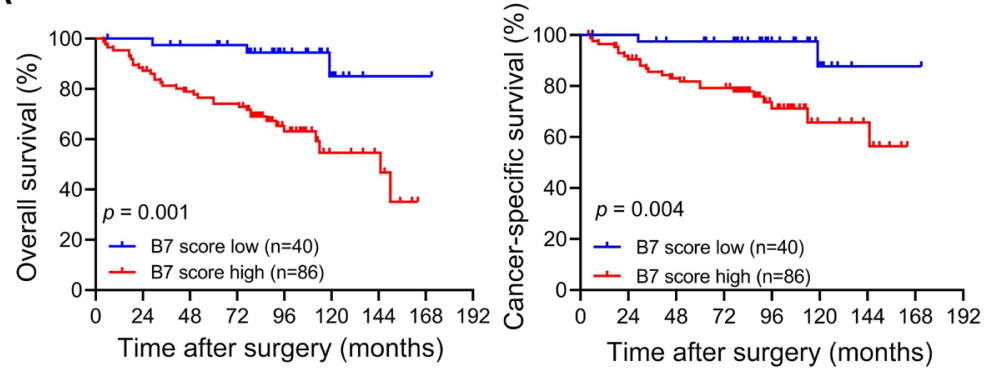

Training Cohort
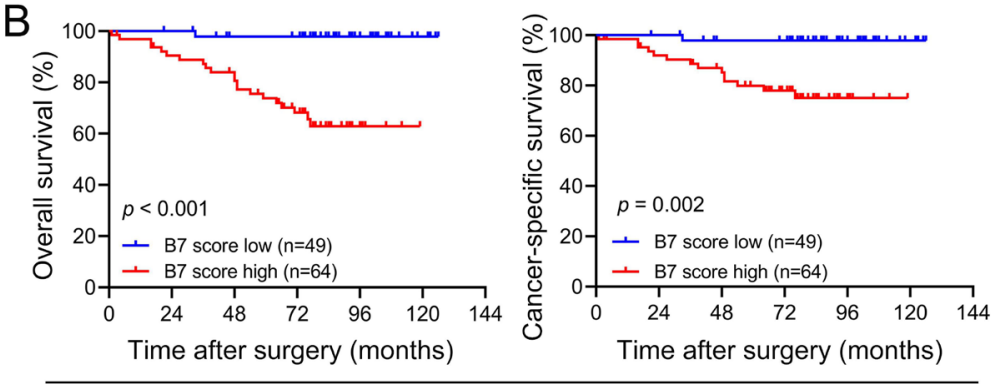

Validation Cohort

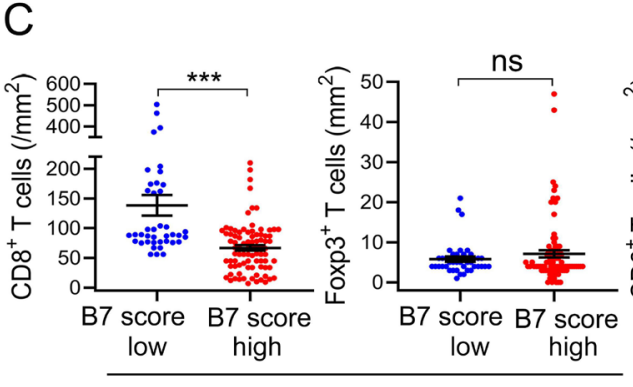

Training cohort

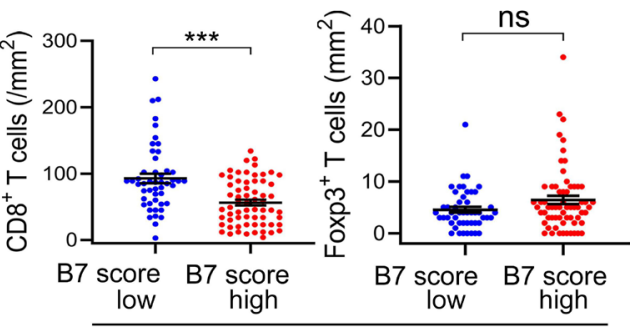

Validation cohort

Figure 4 The correlation of B7 score with overall survival (OS), cancer-specific survival (CSS) and tumor-infiltrating immune cells (TILs). (A-B) OS and CSS according to B7 score in indicated cohort. (C) The counts of CD8 ${ }^{+}$and Foxp3 ${ }^{+}$TILs in tumors with different B7 score in indicated cohorts. Error bars indicate median with SEM, ${ }^{\star *} \mathrm{p}<0.01,{ }^{* \star *} \mathrm{p}<0.001$, ns, no significance.

PCa in the future. Specifically, simultaneous blockade of the B7-H3 and HHLA2 pathways may be an optimal therapeutic schedule for patients with PCa with high B7-H3 and HHLA2 expression. However, for patients with overexpression of one marker, a single inhibitor targeting the corresponding maker may be sufficient.

Accordingly, there is still no consensus on the immunological function of B7-H3 and HHLA2 because both protumor and antitumor roles of these proteins have been postulated. For example, a previous study indicated that B7-H3 was involved in suppression of interferon- $\gamma$ secretion. Consistently, antagonizing B7-H3 increased $\mathrm{CD}^{+} \mathrm{T}$ cell aggregation and antitumor response in mouse models. ${ }^{356}$ However, paradoxically, in another early study, B7-H3 was suggested to be a costimulator of T cells, facilitating cytokine production. ${ }^{18}$ Likewise, HHLA2 has been proved to promote $\mathrm{T}$ cell growth and cytokine secretion via an AKT-dependent signaling cascade. ${ }^{24}$ In contrast, HHLA2 was also reported to inhibit the proliferation both $\mathrm{CD}^{+}$and $\mathrm{CD}^{+}{ }^{+} \mathrm{T}$ cells and reduce cytokine production by $\mathrm{T}$ cells. ${ }^{23}$ The paradoxical dual function of both B7-H3 and HHLA2 among heterogeneous malignancies may be resulted from differential expression of corresponding activating or inhibitory ligands on immune cells or differential infiltration of sets of immune cells. In this study, we comprehensively evaluated the association between HHLA2 and B7-H3 and the TILs. Overexpression of both B7-H3 and HHLA2 was significantly associated with fewer CD8 ${ }^{+}$TILs. High expression of HHLA2 was also accompanied by prominent Foxp $3^{+}$TILs in the validation cohort. These data demonstrate that both B7-H3 and HHLA2 are associated with a suppressive immune microenvironment within PCa. Meanwhile, enoblituzumab, an anti-B7-H3 monoclonal antibody, exhibited antitumor activity in preclinical tumor models of $\mathrm{PCa} .{ }^{37}$ Thus, it is convincing that both B7-H3 and HHLA2 mainly perform immunosuppressive functions within PCa tissues.

Recently, with the advent of precision medicine, numerous immune classifications have been proposed for guiding immunotherapy. Among them, the proposed theory from Teng $e t a l$ has been widely recognized across cancer types. ${ }^{38}$ According to this theory, tumors are 
Table 4 Multivariate analyses of prognostic factors correlated with OS and CSS with regard to B7 score

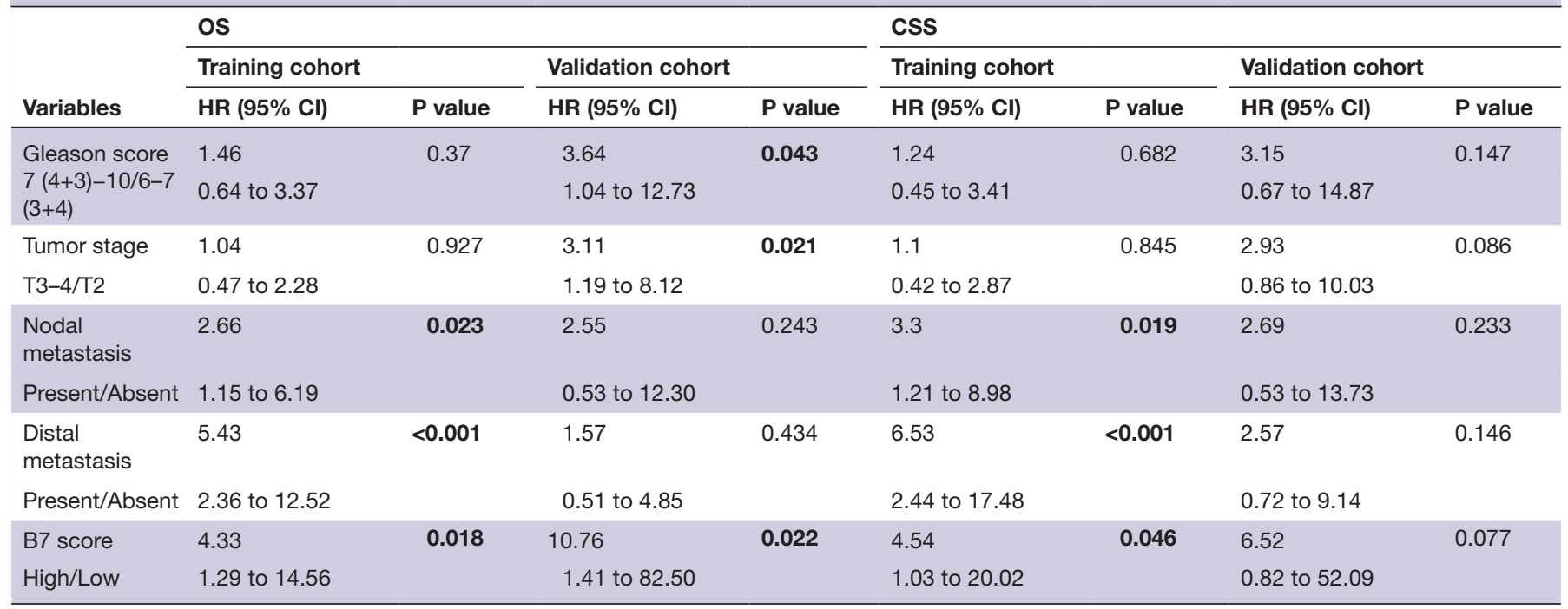

$P$ values $<0.05$ marked in bold font are statistically significant.

CSS, cancer-specific survival; OS, overall survival.

classified into four categories as follows: tumors with adaptive immune resistance, tolerance, immunological ignorance and intrinsic induction, based on PD-L1 expression and TIL infiltration. However, this immunophenotype is not suitable for some 'cold' cancers, most notably PCa because of the low to no PD-L1 expression. To optimize this immunophenotype, we replaced PD-L1 expression with a new B7 score and examined the potential prognostic impact of the combined $\mathrm{B} 7$ score and $\mathrm{CD} 8^{+}$TIL status in patients with PCa. Our data indicate a significant association between stratification based on the B7 score and $\mathrm{CD}^{+}$TILs and OS and CSS. For example, patients
A
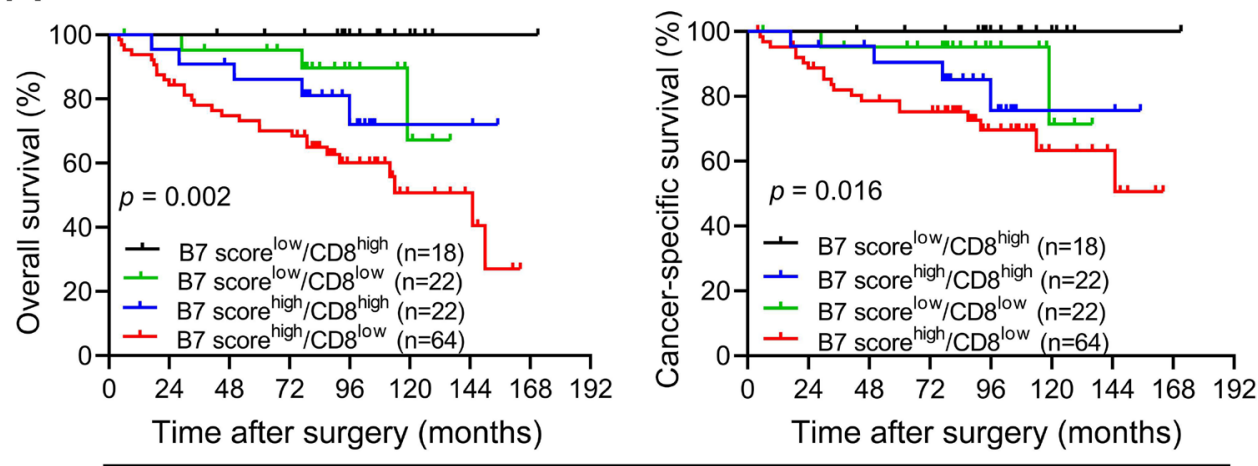

Training cohort

B

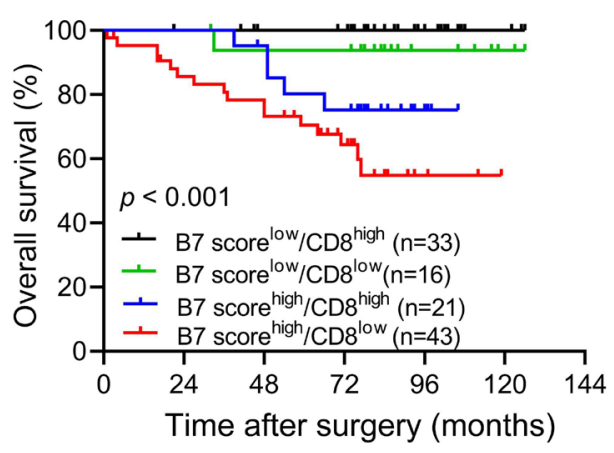

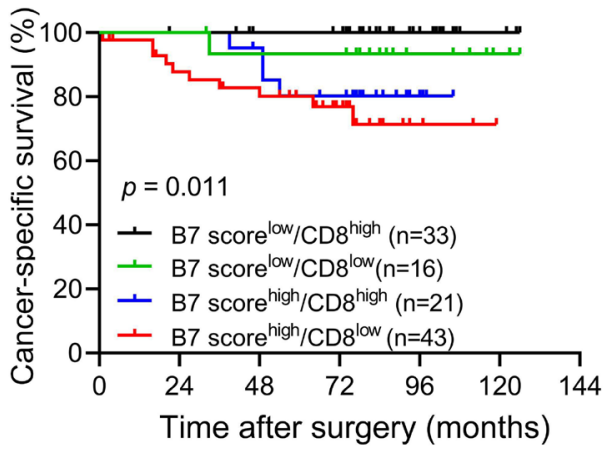

Time after surgery (months)

\section{Validation cohort}

Figure 5 Association of new immune classification with overall survival (OS) and cancer-specific survival (CSS) depicted by Kaplan-Meier survival curves. (A-B) OS and CSS according to new immune classification in indicated cohort. 
with a high $\mathrm{B} 7$ score and less $\mathrm{CD} 8^{+}$TIL infiltration may be considered as a 'super-cold' tumor, which is insensitive to existing clinical immunotherapy and associated with the poorest prognosis. However, it is possible that patients with low $\mathrm{B} 7$ scores and high $\mathrm{CD} 8^{+}$TIL infiltration do not require subsequent adjuvant $\mathrm{ADT}$ and/or chemoradiotherapy, because of their favorable prognosis. Taken together, these results may have important implications for the design of immunotherapy studies in the future.

The present study has several limitations. First, as a retrospective study, selection bias is inevitable. However, dualcenter cohorts would make our data more convincing. Second, the expression level of the immune makers evaluated in the present study were dichotomized as high or low according to the corresponding cut-off values, which were only based on the H-score in both cohorts. Thus, to increase reliability, a larger sample size cohort is needed to identify the exact cut-off. Last, despite the significant correlations among immune markers, the exact colocalization among immune markers is still unclear. Thus, multiple immunofluorescence assays are needed to confirm the associations among different immune markers.

In summary, we demonstrated that both $\mathrm{B} 7-\mathrm{H} 3$ and HHLA2 were associated with immunosuppressive microenvironment, and the $\mathrm{B} 7$ score could be used as an independent prognostic factor for PCa. Most importantly, we established a new immune classification on the basis of B7 score and $\mathrm{CD}^{+}$TILs, which might significantly stratify OS and CSS in patients with PCa.

\section{Author affiliations}

${ }^{1}$ Department of Urology, Sun Yat-sen Memorial Hospital, Sun Yat-sen University, Guangzhou, Guangdong, China

${ }^{2}$ Guangdong Provincial Key Laboratory of Malignant Tumor Epigenetics and Gene Regulation, Sun Yat-Sen Memorial Hospital, Sun Yat-Sen University, Guangzhou, Guangdong, China

${ }^{3}$ Department of urology, Sun Yat-sen University Cancer Center, Guangzhou, Guangdong, China

${ }^{4}$ Department of Radiology, Massachusetts General Hospital, Boston, Massachusetts, USA

${ }^{5}$ Department of Oncology, Albert Einstein College of Medicine, Bronx, New York, USA ${ }^{6}$ Guangdong Provincial Clinical Research Center for Urological Diseases, Sun YatSen Memorial Hospital, Sun Yat-Sen University, Guangzhou, Guangdong, China ${ }^{7}$ Department of Urology, The Sixth Affiliated Hospital of Guangzhou Medical University, Qingyuan People's Hospital, Qingyuan, Guangdong, china

Acknowledgements This work was supported by grants from Guangdong Science and Technology Department (2017B030314026). We would like to thank Dr Jianchang Fu and Dr Yuan-zhong Yang from Department of Pathology, SYSUCC for their assistance in IHC score.

Contributors Conception and design: $\mathrm{HH}, \mathrm{JH}$ and $\mathrm{KX}$. Performed the experiments: QZ and KL. Acquisition and interpretation of data: all authors. Drafting the article: QZ and YL. Manuscript reviewing, editing and approval of the manuscript: all authors.

Funding This study was supported by the National Natural Science Foundation of China (81672550, 81974395, 81702527, 81802527); Guangdong Basic and Applied Basic Research Foundation (2019A1515011437); Guangzhou Science and Technology Cooperation Program (Foreign Research and Development Cooperation) (201807010087); Sun Yat-sen University Clinical Research 5010 Program (2019005); Guangdong Provincial Clinical Research Center for Urological Disease (2020B1111170006); Sun Yat-sen Clinical Research Cultivating Program (201702) to $\mathrm{HH}, \mathrm{KL}$ or $\mathrm{YL}$.
Competing interests No, there are no competing interests.

Patient consent for publication Not required.

Ethics approval This study was approved by the Clinical Research Ethic Committee of Sun Yat-sen Memorial Hospital (SYSEC-KY-KS-2020-201) and Sun Yat-sen University Cancer Center (2021-FXY-139).

Provenance and peer review Not commissioned; externally peer reviewed.

Data availability statement Data are available on reasonable request. None.

Supplemental material This content has been supplied by the author(s). It has not been vetted by BMJ Publishing Group Limited (BMJ) and may not have been peer-reviewed. Any opinions or recommendations discussed are solely those of the author(s) and are not endorsed by BMJ. BMJ disclaims all liability and responsibility arising from any reliance placed on the content. Where the content includes any translated material, BMJ does not warrant the accuracy and reliability of the translations (including but not limited to local regulations, clinical guidelines, terminology, drug names and drug dosages), and is not responsible for any error and/or omissions arising from translation and adaptation or otherwise.

Open access This is an open access article distributed in accordance with the Creative Commons Attribution Non Commercial (CC BY-NC 4.0) license, which permits others to distribute, remix, adapt, build upon this work non-commercially, and license their derivative works on different terms, provided the original work is properly cited, appropriate credit is given, any changes made indicated, and the use is non-commercial. See http://creativecommons.org/licenses/by-nc/4.0/.

\section{ORCID iD}

Hai Huang http://orcid.org/0000-0002-2013-073X

\section{REFERENCES}

1 Siegel RL, Miller KD, Jemal A. Cancer statistics, 2019. CA A Cancer $J$ Clin 2019;69:7-34.

2 Litwin MS, Tan $\mathrm{H}-\mathrm{J}$. The diagnosis and treatment of prostate cancer: a review. JAMA 2017;317:2532-42.

3 Katzenwadel A, Wolf P. Androgen deprivation of prostate cancer: leading to a therapeutic dead end. Cancer Lett 2015;367:12-17.

4 Wong YNS, Ferraldeschi R, Attard G, et al. Evolution of androgen receptor targeted therapy for advanced prostate cancer. Nat Rev Clin Oncol 2014;11:365-76.

5 Claessens F, Helsen C, Prekovic S, et al. Emerging mechanisms of enzalutamide resistance in prostate cancer. Nat Rev Urol 2014;11:712-6.

6 Motzer RJ, Escudier B, McDermott DF, et al. Nivolumab versus everolimus in advanced renal-cell carcinoma. $N$ Engl $\mathrm{J}$ Med 2015;373:1803-13.

7 Rizvi NA, Mazières J, Planchard D, et al. Activity and safety of nivolumab, an anti-PD-1 immune checkpoint inhibitor, for patients with advanced, refractory squamous non-small-cell lung cancer (CheckMate 063): a phase 2, single-arm trial. Lancet Oncol 2015;16:257-65

8 Robert C, Long GV, Brady B, et al. Nivolumab in previously untreated melanoma without BRAF mutation. N Engl J Med 2015;372:320-30.

9 Axelrod ML, Johnson DB, Balko JM. Emerging biomarkers for cancer immunotherapy in melanoma. Semin Cancer Biol 2018;52:207-15.

10 Fuchs CS, Doi T, Jang RW, et al. Safety and efficacy of pembrolizumab monotherapy in patients with previously treated advanced gastric and gastroesophageal junction cancer: phase 2 clinical KEYNOTE-059 trial. JAMA Oncol 2018;4:e180013.

11 Roth TJ, Sheinin Y, Lohse CM, et al. B7-H3 ligand expression by prostate cancer: a novel marker of prognosis and potential target for therapy. Cancer Res 2007;67:7893-900.

12 Jafari S, Molavi O, Kahroba $\mathrm{H}$, et al. Clinical application of immune checkpoints in targeted immunotherapy of prostate cancer. Cell Mol Life Sci 2020;77:3693-710.

13 Martin AM, Nirschl TR, Nirschl CJ, et al. Paucity of PD-L1 expression in prostate cancer: innate and adaptive immune resistance. Prostate Cancer Prostatic Dis 2015;18:325-32.

14 Sun T-W, Gao Q, Qiu S-J, et al. B7-H3 is expressed in human hepatocellular carcinoma and is associated with tumor aggressiveness and postoperative recurrence. Cancer Immunol Immunother 2012;61:2171-82.

15 Arigami T, Narita N, Mizuno R, et al. B7-H3 ligand expression by primary breast cancer and associated with regional nodal metastasis. Ann Surg 2010;252:1044-51.

16 Yim J, Koh J, Kim S, et al. Effects of B7-H3 expression on tumourinfiltrating immune cells and clinicopathological characteristics in non-small-cell lung cancer. Eur J Cancer 2020;133:74-85. 
17 Loos M, Hedderich DM, Ottenhausen M, et al. Expression of the costimulatory molecule $\mathrm{B} 7-\mathrm{H} 3$ is associated with prolonged survival in human pancreatic cancer. BMC Cancer 2009;9:463.

18 Chapoval Al, Ni J, Lau JS, et al. B7-H3: a costimulatory molecule for T cell activation and IFN-gamma production. Nat Immunol 2001;2:269-74.

19 Prasad DVR, Nguyen T, Li Z, et al. Murine B7-H3 is a negative regulator of T cells. J Immunol 2004;173:2500-6.

20 Suh $\mathrm{W}-\mathrm{K}$, Wang SX, Jheon $\mathrm{AH}$, et al. The immune regulatory protein B7-H3 promotes osteoblast differentiation and bone mineralization. Proc Natl Acad Sci U S A 2004;101:12969-73.

21 Hashiguchi M, Kobori $\mathrm{H}$, Ritprajak $\mathrm{P}$, et al. Triggering receptor expressed on myeloid cell-like transcript 2 (TLT-2) is a counterreceptor for B7-H3 and enhances T cell responses. Proc Natl Acad Sci U S A 2008;105:10495-500.

22 Zang X, Thompson RH, Al-Ahmadie HA, et al. B7-H3 and B7x are highly expressed in human prostate cancer and associated with disease spread and poor outcome. Proc Natl Acad Sci U S A 2007; 104:19458-63.

23 Zhao R, Chinai JM, Buhl S, et al. HHLA2 is a member of the B7 family and inhibits human CD4 and CD8 T-cell function. Proc Natl Acad Sci U S A 2013;110:9879-84.

24 Zhu Y, Yao S, lliopoulou BP, et al. B7-H5 costimulates human T cells via CD28H. Nat Commun 2013;4:2043.

25 Zhou Q-H, Li K-W, Chen X, et al. HHLA2 and PD-L1 co-expression predicts poor prognosis in patients with clear cell renal cell carcinoma. J Immunother Cancer 2020;8:e000157.

26 Boor PPC, Sideras K, Biermann K, et al. HHLA2 is expressed in pancreatic and ampullary cancers and increased expression is associated with better post-surgical prognosis. $\mathrm{Br} J$ Cancer 2020;122:1211-8.

27 Cheng $\mathrm{H}$, Janakiram M, Borczuk A, et al. HHLA2, a new immune checkpoint member of the B7 family, is widely expressed in human lung cancer and associated with EGFR mutational status. Clin Cancer Res 2017;23:825-32.
28 Jing C-Y, Fu Y-P, Yi Y, et al. HHLA2 in intrahepatic cholangiocarcinoma: an immune checkpoint with prognostic significance and wider expression compared with PD-L1. $J$ Immunother Cancer 2019;7:77.

29 Janakiram M, Chinai JM, Fineberg S, et al. Expression, clinical significance, and receptor identification of the newest $B 7$ family member HHLA2 protein. Clin Cancer Res 2015;21:2359-66.

30 Zhou Q-H, Han H, Lu J-B, et al. Up-regulation of indoleamine 2,3-dioxygenase 1 (IDO1) expression and catalytic activity is associated with immunosuppression and poor prognosis in penile squamous cell carcinoma patients. Cancer Commun 2020;40:3-15.

31 Läubli H, Balmelli C, Kaufmann L, et al. Influenza vaccination of cancer patients during PD-1 blockade induces serological protection but may raise the risk for immune-related adverse events. $J$ Immunother Cancer 2018:6:40.

32 Yang Y, Attwood K, Bshara W, et al. High intratumoral CD8 ${ }^{+}$T-cell infiltration is associated with improved survival in prostate cancer patients undergoing radical prostatectomy. Prostate 2021;81:20-8.

33 Chavin G, Sheinin Y, Crispen PL, et al. Expression of immunosuppresive B7-H3 ligand by hormone-treated prostate cancer tumors and metastases. Clin Cancer Res 2009;15:2174-80.

34 Benzon B, Zhao SG, Haffner MC, et al. Correlation of B7-H3 with androgen receptor, immune pathways and poor outcome in prostate cancer: an expression-based analysis. Prostate Cancer Prostatic Dis 2017;20:28-35.

35 Sun X, Vale M, Leung E, et al. Mouse B7-H3 induces antitumor immunity. Gene Ther 2003;10:1728-34.

36 Yamato I, Sho M, Nomi T, et al. Clinical importance of B7$\mathrm{H} 3$ expression in human pancreatic cancer. $\mathrm{Br} \mathrm{J}$ Cancer 2009;101:1709-16.

37 Loo D, Alderson RF, Chen FZ, et al. Development of an Fc-enhanced anti-B7-H3 monoclonal antibody with potent antitumor activity. Clin Cancer Res 2012;18:3834-45.

38 Teng MWL, Ngiow SF, Ribas A, et al. Classifying cancers based on T-cell infiltration and PD-L1. Cancer Res 2015;75:2139-45. 